\title{
Avaliação Da Qualidade Assistencial De Pacientes Com Insuficiência Cardíaca Em Hospital Público Terciário No Brasil
}

\author{
Wajner, A.; Pereira, G.A.R.; Landenberger, T.; Peruzzo, N.C.; Maccarini, \\ J.L.;Souza, V.; Polanczyk,, C.A.; \\ Apresentador: Guilherme Augusto Reissig Pereira
}

\section{Resumo}

Introdução: A Insuficiência cardíaca (IC) representa a maior causa cardiovascular de morbidade hospitalar no Brasil. Embora sociedades médicas internacionais recomendem o acompanhamento de indicadores de qualidade assistencial na prática clínica, sua adesão tem sido controversa, limitada e seus resultados não estão adequadamente estudados em diversos contextos. Assim objetivamos aferir parâmetros de qualidade assistencial em pacientes hospitalizados com IC e analisar a relação entre a adesão a estas medidas e as taxas de visitas ao serviço de emergência e reinternações em 30 dias pós-alta no cenário hospitalar público brasileiro. Métodos: Realizou-se estudo de coorte histórico com utilização de dados secundários em 2070 pacientes que internaram com o diagnóstico de IC estabelecido através do registro pelo médico assistente do Índice de Comorbidade de Charlson (ICCharlson) preenchido compulsoriamente no prontuário eletrônico no momento da internação e alta hospitalar no período de 2009-2010. Foram coletados dados demográficos, assistenciais e indicadores hospitalares. A coleta de dados foi realizada por equipe previamente treinada através da revisão sistemática de prontuários eletrônicos com protocolo de coleta de dados informatizado e totalmente integrado ao prontuário eletrônico do hospital. As análises estatísticas formam conduzidas pelo SPSS Basic versão 19.0. Resultados: Houve, em toda amostra, acentuadas medianas de ICCharlson (5,0 IQ 25-75\%:4-7) e de tempo de internação (14 dias IQ 25-75\%:10-22), constatando-se $13 \%$ de óbitos hospitalares. Doença cerebrovascular, um ICCharlson elevado e um menor tempo de permanência foram preditores de reinternação. Em relação aos indicadores assistenciais, as instruções na nota de alta foram adequadas em apenas $13 \%$ dos casos e, em pacientes com Fração de Ejeção (FE) reduzida, 87\% tinham prescrição de IECA/BRA e $66 \%$ de beta-bloqueadores na alta. Não houve impacto dessas medidas na taxa de reinternação e/ou visita a emergência, independente da FE. Conclusões: Pacientes internados com IC em hospital público terciário brasileiro apresentam significativa morbimortalidade quando comparado à literatura internacional. Observaram-se taxas de medidas clássicas de qualidade assistencial em pacientes com IC bastante abaixo das metas internacionais. Por fim, esses parâmetros de qualidade não foram associados com diminuição de reinternação ou de consulta precoce à emergência.

\section{Referência:}

Wajner, A.; Pereira, G.A.R.; Landenberger, T.; Peruzzo, N.C.; Maccarini, J.L.;Souza, V.; Polanczyk,, C.A.; Avaliação Da Qualidade Assistencial De Pacientes Com Insuficiência Cardíaca Em Hospital Público Terciário No Brasil. In: II Congresso Brasileiro de Medicina Hospitalar - II CBMH [= Blucher Medical Proceedings, vol.1, num.5] São Paulo: Editora Blucher, 2014. p.95

DOI 10.5151/medpro-II-cbmh-094 